\title{
Changes in the Level of Nursing Students' Empathy During Four Years Education
}

\author{
Maryam Sedaghati Kesbakhi (iD) ${ }^{1, *}$ and Camelia Rohani (iD) ${ }^{2,3}$ \\ ${ }^{1}$ Department of Nursing, School of Medical Sciences, Tonekabon Branch, Islamic Azad University, Tonekabon, Iran \\ ${ }^{2}$ Department of Community Health Nursing, School of Nursing and Midwifery, Shahid Beheshti University of Medical Sciences, Tehran, Iran \\ ${ }^{3}$ Department of Palliative Care, Ersta Sköndal Bräcke University College, Campus Ersta, Stigbergsgatan 30, Box 11189, SE-100 61, Stockholm, Sweden \\ "Corresponding author: PhD, Assistant Professor, Department of Nursing, School of Medical Sciences, Tonekabon Branch, Islamic Azad University, Tonekabon, Iran. Email: \\ maryam.sedaghati77@gmail.com
}

Received 2020 July 05; Accepted 2020 September 09.

\begin{abstract}
Background: The findings on changes in the level of nursing students' empathy during the university education are contradictory, and it's not clear whether it decreases/increases after four years of education.

Objectives: The current study aimed to investigate the level of nursing students' empathy during different years of education.

Methods: In this descriptive study, 122 undergraduate nursing students from the first to the fourth year of the program are included. Data were collected using the Jefferson Scale of Empathy Nursing Student Version-R and analyzed by the descriptive and analytical tests in SPSS version 21.

Results: The mean score of empathy was $91.8 \pm 28.7$. The level of empathy significantly declines in the fourth year of education, compared to the first year $(\mathrm{P}<0.001)$.

Conclusions: This study showed that the level of empathy of nursing students significantly declines in the fourth year, so exploring its causes would be useful. Also, empathy should be introduced to the nursing students as one of the standards of clinical competency using strategies such as education for empathic communication with the patient in nursing training programs.
\end{abstract}

Keywords: Empathy, Empathic Communication, Nursing Student, Patient.

\section{Background}

Communication is a crucial component of the relations between health care providers, including nursing students, and patients that affects patients' and families' hope (1). Hence, communication can be considered as an important aspect of nursing care, so that establishing an effective relationship with patients through addressing their concerns, understanding, empathy, and providing comfort and support, is as important as having information about illness and treatment (2). Empathy is a communication skill that uses to control, sharpen, support, understand, rebuild, and reflect the perception of the patient's thoughts and feelings. Long-term trust and communication are the prerequisites of establishing empathy (3). Having empathy communication skills is necessary for nursing students, as their skills directly affect the patient's satisfaction and influence their health outcomes (4). Empathy is an important ability to fit the person with the feelings and thoughts of others, link the person with the social world, helping others, and to prevent harm to others. Empathy also stimulates social behaviors that increase the co- hesion of teams (5). Cognitive empathy means being aware of sensation and awareness of others' feelings, while the purpose of emotional empathy is to properly perceive the thoughts and feelings of others and showing a suitable response to them (6).

A review study reported contradictory results about changes in the level of nursing students' empathy $(7,8)$ and other students in the healthcare field during academic years of education $(9,10)$. Nevertheless, several studies indicated that as the years of education increase, the level of empathy declines $(7,9,10)$. Since only one study was found on this topic in Iran (11) (after an extensive search of internal and international databases), the authors decided to design new research in this area.

\section{Objectives}

The current study aimed to investigate the level of empathy and its changes in undergraduate nursing students from the first year to the fourth year. 


\section{Methods}

In this descriptive study, 122 undergraduate nursing students from the first to the fourth year of the program at the Islamic Azad University, Tonekabon branch, are included. Since the university accepts 35 nursing students each year, using the census methodology, all of them were included. The first author invited all attending undergraduate nursing students from the first to the fourth year of academic education to participate in this study by installing an invitation poster on the wall of the main entrance of the university. First, the objectives of the study were explained to them, and, if agreeing, written informed consent was taken from them. Afterward, questionnaires were distributed among 140 nursing students, that 18 of them were excluded due to incompleteness. The participation rate was as follows (as mentioned before, each year, the university accepts only 35 nursing students): fourth year $=30$, third year $=32$, second year $=29$, and first year $=31$.

\subsection{Measurements}

\subsubsection{Demographic Information Sheet}

Before filling out the Jefferson empathy scale, students were asked to complete a demographic form, including age, gender, marital status, and the education year.

\subsubsection{Jefferson Scale of Empathy Nursing Student Version-R (JSE- NS Version $R$ )}

This scale is based on the Jefferson Physician Empathy Scale that consists of 20 items with a 7-point Likert scale. Each item is assigned a score ranging from 1 (strongly disagree) to 7 (strongly agree). JSE-NS version $\mathrm{R}$ has three factors; "perspective taking" (10 items), "compassionate care" (8 items), and "standing in patient's shoes" ( 2 items). To calculate the total score, 10 items must be reversed (1, 3, 6-8, 1115). The validity and reliability of the Persian version of the JSE- NS version R are confirmed in a previous study (12).

However, in the psychometrics study of the Persian version of this scale, four factors were identified, i.e., "perspective taking", "compassionate care", "standing in patient's shoes", and "metacognitive" (12). The total score ranges from 20 to 140. The higher the score, the higher the empathy. The reliability of the English version of the scale was confirmed using the internal consistency and calculating the Cronbach's alpha coefficient in a sample of American nursing students ( $\alpha=0.77$ ) (16). In the present study, the reliability of the JSE-NS version $\mathrm{R}$ is assessed in a sample of 122 nursing students using Cronbach's alpha coefficient $(\alpha$ $=0.93$ ).

\subsection{Data Analysis}

The Kolmogorov-Smirnov test was used to assess the normality of the distribution of data. The result showed a normal distribution $(\mathrm{P}>0.05)$. Descriptive statistics and independent $t$-test, Analysis of Variance (ANOVA), and Tukey Post Hoc test were used to analyze the data.

\section{Results}

The mean age of nursing students in all academic years was $21.6 \pm 2.5$ years. Most of the participants were female (89.3\%) and single (85.2\%) (Table 1). The mean scores of nursing students' empathy (calculated by the JSE-NS version $\mathrm{R}$ ) across different academic years and in all academic years are reported in Table 2 .

Classification of students' empathy scores on percentiles showed that for $76.7 \%$ of students of the fourth year of education, the scores were grouped in less than 50 percentile. Only $32.3 \%$ of the first-year students, $27.6 \%$ of the second-year students, and $25 \%$ of the third-year students were grouped between percentiles of 50 and 75, respectively. While the empathy score of the fourth year students was not in this range (Table 3 ).

Based on the independent t-test, students who were aged 20 years (or more), single, and female had higher levels of empathy than those younger than 20 years, male, and married. The results of ANOVA showed that students' empathy was higher in the first year of education than in other years. The Tukey Post Hoc test showed that the empathy of the second-year students was less than the first year, and the lowest level of students' empathy was found in the students of the fourth year of education (Table 4).

\section{Discussion}

In this study, the average empathy of nursing students was different from other studies, with similar scales. A study conducted on nursing students in the US reported an average empathy of $114 \pm 11.5$ (16). A similar study that intended to perform psychometric analysis of the JSE- NS version $\mathrm{R}$ has investigated 598 American nursing students and reported an average empathy of $114.5 \pm 10.9$ (13). Also, the average empathy of nursing students in Greece was reported as $88.6 \pm 8.9(17))$. The results of the present study showed that the higher the students' academic year, the lower the level of empathy. In other words, exposure of students with more patients during the time decreases their empathy. It may be related to the continuous communication of students with patients in clinical environments, gaining more autonomy, and decreased supervision of clinical faculties in the second and third years of education, compared to the first year (7). A study conducted 


\begin{tabular}{|c|c|c|c|c|c|}
\hline Variable/Classification & Education Year 1, No. (\%) & Education Year 2, No. (\%) & Education Year 3, No. (\%) & Education Year 4, No. (\%) & Sum (\%) \\
\hline \multicolumn{6}{|l|}{ Age (year) } \\
\hline$<20$ & $21(67.7)$ & $4(13.8)$ & $0(0)$ & $0(0)$ & $25(20.5)$ \\
\hline$\leq 20$ & $10(32.3)$ & $25(86.2)$ & $32(100)$ & $30(100)$ & $97(79.5)$ \\
\hline \multicolumn{6}{|l|}{ Gender } \\
\hline Male & $0(0)$ & $5(17.2)$ & $8(25)$ & $0(0)$ & $13(10.7)$ \\
\hline Female & $31(100)$ & $24(82.8)$ & $24(75)$ & $30(100)$ & $109(89.3)$ \\
\hline \multicolumn{6}{|l|}{ Marital Status } \\
\hline Single & $30(96.8)$ & $27(93.1)$ & $27(84.3)$ & $20(66.7)$ & $104(85.2)$ \\
\hline Married & $1(3.2)$ & $2(6.9)$ & $5(15.7)$ & $10(33.3)$ & $18(14.8)$ \\
\hline Education Year & \multicolumn{2}{|c|}{ JSE-NS Version R, Mean \pm SD } & Median & \multicolumn{2}{|c|}{ Maximum } \\
\hline First & \multicolumn{2}{|r|}{$112.9 \pm 10.0$} & 113 & \multicolumn{2}{|c|}{135} \\
\hline Second & \multicolumn{2}{|r|}{$101.7 \pm 13.9$} & 105 & \multicolumn{2}{|c|}{121} \\
\hline Third & \multicolumn{2}{|r|}{$105.7 \pm 11.9$} & 105 & \multicolumn{2}{|c|}{128} \\
\hline Fourth & \multicolumn{2}{|r|}{$45.5 \pm 1.8$} & 46 & \multicolumn{2}{|c|}{48} \\
\hline All years & \multicolumn{2}{|r|}{$91.8 \pm 28.7$} & 101.5 & \multicolumn{2}{|c|}{135} \\
\hline
\end{tabular}

\begin{tabular}{|c|c|c|c|c|}
\hline Empathy Score on Percentiles & Education Year 1, No. (\%) & Education Year 2, No. (\%) & Education Year 3, No. (\%) & Education Year 4, No. (\%) \\
\hline$<\mathbf{2 5}$ & $7(22.6)$ & $6(20.7)$ & $8(25.0)$ & $8(26.7)$ \\
\hline $25-50$ & $9(29.0)$ & $9(31.0)$ & $8(25.0)$ & $15(50.0)$ \\
\hline $50-75$ & $10(32.3)$ & $8(27.6)$ & $8(25.0)$ & $0(0)$ \\
\hline$>75$ & $5(16.1)$ & $6(20.7)$ & $8(25.0)$ & $7(23.3)$ \\
\hline
\end{tabular}

in the UK found that the empathy of third-year nursing students was lower than those in the first year (18). Contradictory results were found in earlier studies. For example, a study conducted on nursing students of the Guilan University of Medical Science reported no statistically significant difference between the level of empathy of first-year students and those in the fourth year (11). Besides, nursing students in the fourth academic year of education at the University of Ordu in Turkey reported higher empathy scores than those in the first-year students (8).

This study showed that the empathy of the third year nursing students is higher than the second-year students. However, the results of a study on pharmacology students in Malaysia found that third and fourth-year students had lower empathy compared to the first and second-year students (19). But, the empathy of the third-year students of pharmacology in the UK was significantly higher than that of the first-year students (18). Another study in India showed that the level of empathy is inversely associated with the years of education (14). Two studies conducted on medical students in The US and Shiraz University of Medical Sciences (Iran) reported that the higher the education year, the lower the level of empathy $(9,10)$. Hojat et al. (15) discussed about the following factors which may reduce medical students' empathy; lack of appropriate role models, negative attitudes toward clinical competencies, longterm presence in the clinical settings, threatening or risky educational environments, heavy educational responsibilities, or clinical duties, and negative reactions of patients to students' empathy. Rosen et al. reported the following factors; different aspects of stressful practices such as long hours of clinical work and sleep deprivation, dependence on technology for diagnosis, short-term hospitalization of the patients, and limited interactions between students and patients (20).

Investigating demographic characteristics of nursing students and their empathy scores revealed that those who are 20 years old and older, single, and female have higher 
Table 4. Classification of Demographic Characteristics According to the Empathy Score by the Jefferson Scale in Nursing Students $(\mathrm{N}=122)$

\begin{tabular}{|c|c|c|c|}
\hline Variable/Classification & Number (\%) & $\begin{array}{c}\text { Empathy Score, } \\
\text { Mean } \pm \text { SD }\end{array}$ & PValue \\
\hline Age $(\text { year })^{a}$ & & & $<0.001$ \\
\hline$<20$ & $25(20.5)$ & $81.6 \pm 30.9$ & \\
\hline$\leq 20$ & $97(79.5)$ & $108.0 \pm 14.1$ & \\
\hline Gender $^{\mathrm{a}}$ & & & $<0.01$ \\
\hline Male & $13(10.7)$ & $90.6 \pm 29.9$ & \\
\hline Female & $109(89.3)$ & $102.1 \pm 12.6$ & \\
\hline Education year $^{\text {b }}$ & & & $<0.001$ \\
\hline 1 & $31(25.4)$ & $112.9 \pm 10.0$ & \\
\hline 2 & $29(23.8)$ & $101.7 \pm 13.9$ & \\
\hline 3 & $32(26.2)$ & $105.7 \pm 11.9$ & \\
\hline 4 & $30(24.6)$ & $45.5 \pm 1.8$ & \\
\hline Marital status & & & 0.449 \\
\hline Single & $104(85.2)$ & $83.9 \pm 10.3$ & \\
\hline Married & $18(14.8)$ & $79.3 \pm 12.1$ & \\
\hline
\end{tabular}

scores than students younger than 20 years, male, and married. A research conducted in Australia on undergraduate paramedic/nursing students reported that students aged 30-36 and 31-35 years had higher scores than their younger classmates (21). Higher empathy of older students can be attributed to their higher experiences in life, which in turn increases their empathy (16). Also, the acquisition of experiences such as love, loss, regret, entanglement, pain, and loneliness leads to more attention to the effects of these experiences throughout the life on others (21). A study that used the "Empathic Tendency Scale" to measure the empathy of nursing students has reported that the empathy of those younger than 20 years was lower than those aged 21 - 30 years (8). While (22), found that increased age was not associated with the level of empathy of Brazilian nurses.

A review of gender-focused empathy research has shown that women are generally more empathetic than men $(14,16,23-26)$. Another study conducted on medical students in Bangladesh reported that the empathy score of females was higher than males (27), which can be attributed to females abilities to better manage confrontations with life stressors (28). This gender difference can also be attributed to sexual bio-evolutionary characteristics, interpersonal care styles, socialization, and gender role expectations (29). In the present study, single nursing students had higher empathy scores than their married counterparts, but a similar study on oncology nurses conducted in Iran reported higher scores for married nurses
(30). However, in another study on oncology nurses in Turkey, marital status was not associated with nurses' empathy (31). It seems that the low number of married students in our study has resulted in biased results.

\subsection{Conclusions}

This study showed the necessity for teaching clinical empathy in the educational program of nursing students. Although some researchers believe that empathy is an intrinsic characteristic, some studies showed that empathy is associated with increased cognitive dimension through proper education $(30,32,33)$. Since students in the fourth year of education had significantly lower scores than those in the first year, the authors recommend focusing on the causes of this decline in future studies. Thus, empathy with patients should be introduced as a standard skill of clinical competence to the nursing students through strategies such as empathic communication training in the nursing courses program. According to the literature, there are other strategies that can be used to enhance the empathy of nursing students, such as practice for creative writing in nursing, attention to the literature and art, the use of appropriate role models in clinical settings, supervision of students' clinical practice, and encouraging nursing students to use the skill of empathy in dealing with patients (34).

\section{Footnotes}

Authors' Contribution: MSK and CR designed the study. The data were collected, analyzed, and interpreted by MSK and CR. Both authors contributed toward drafting, revising, and approved the final manuscript.

Conflict of Interests: The authors declare no conflict of interest.

Ethical Approval: This research is part of a larger project which was approved by the Research Ethics Committee of the Shahid Beheshti University of Medical Sciences (SBMUZ.REC.1394.55). All necessary permissions were obtained from the Islamic Azad University, Tonekabon Branch, and participants. In addition, nursing students were assured of the confidentiality of the data and voluntary participation in the study.

Funding/Support: This research received no specific grant from any funding agency in the Public, Government, Commercial, or Non-Governmental sectors.

Informed Consent: Verbal and written informed consent was taken from the nursing students before collecting the data. 


\section{References}

1. Reb AM. Transforming the death sentence: elements of hope in women with advanced ovarian cancer. Oncol Nurs Forum. 2007;34(6):E70-81. doi: 10.1188/07.ONF.E70-E81. [PubMed: 18024333].

2. Karimi Moaneghi H, Taheri N, Vaghee S, Behnam Voshani HM. The effect of communication skills training on the quality of nursing care of patients.Thesis Master of Since Degree in Nursing Education: MUMS. 2013.

3. Norfolk T, Birdi K, Walsh D. The role of empathy in establishing rapport in the consultation: a new model. Med Educ. 2007;41(7):690-7. doi: 10.1111/j.1365-2923.2007.02789.x. [PubMed: 17614890].

4. Ward J. The Empathy Enigma: Does It Still Exist? Comparison of Empathy Using Students and Standardized Actors. Nurse Educ. 2016;41(3):134-8. doi: 10.1097/NNE.0000000000000236. [PubMed: 26779692].

5. Rieffe C, Ketelaar L, Wiefferink $\mathrm{CH}$. Assessing empathy in young children: Construction and validation of an Empathy Questionnaire (EmQue). Pers Individ Differ. 2010;49(5):362-7. doi: 10.1016/j.paid.2010.03.046

6. Butter RP. A meta-analysis of empathy training programs for client populations. A dissertation submitted to the faculty of Social Work. The University of Utah; 2010.

7. Ward J, Cody J, Schaal M, Hojat M. The empathy enigma: an empirical study of decline in empathy among undergraduate nursing students. J Prof Nurs. 2012;28(1):34-40. doi: 10.1016/j.profnurs.2011.10.007. [PubMed: 22261603]

8. Günaydın N, Ünsal Barlas G. Determination The Critical Thinking and Empathy Disposition of Nursing Students. Middle Black Sea JHealth Sci. 2015;1(3):1. doi: 10.19127/mbsjohs.27159.

9. Chen D, Lew R, Hershman W, Orlander J. A cross-sectional measurement of medical student empathy. J Gen Intern Med. 2007;22(10):14348. doi: 10.1007/s11606-007-0298-x. [PubMed: 17653807]. [PubMed Central: PMC2305857].

10. Khademalhosseini M, Khademalhosseini Z, Mahmoodian F. Comparison of empathy score among medical students in both basic and clinical levels. J Adv Med Educ Prof. 2014;2(2):88-91. [PubMed: 25512926] [PubMed Central: PMC4235551].

11. Saeidi S, Reza-Masouleh S, Chehrzad MM, Kazem Nejad Leili E. Empathy with Patients Compared between First and Final Year Nursing Students. J Holistic Nurs Midwifery. 2017;27(1):79-85. doi:10.18869/acadpub.hnmj.27.1.79.

12. Sedaghati Kesbakhi M, Rohani C, Mohtashami J, Nasiri M. Validity and Reliability of the Jefferson Scale of Empathy, Nursing Student Version R in a Sample of Iranian Oncology Nurses. Nurs Midwifery Stud. 2016;6(2). doi: 10.5812/nmsjournal.39505.

13. McMillan LR, Shannon DM. Psychometric Analysis of the JSPE Nursing Student Version R: Comparison of Senior BSN Students and Medical Students Attitudes toward Empathy in Patient Care. ISRN Nurs. 2011;2011:726063. doi: 10.5402/2011/726063. [PubMed: 21994895] [PubMed Central: PMC3169335].

14. Nunes P, Williams S, Sa B, Stevenson K. A study of empathy decline in students from five health disciplines during their first year of training. Int J Med Educ. 2011;2:12-7. doi: 10.5116/ijme.4d47.ddbo.

15. Hojat M, Vergare MJ, Maxwell K, Brainard G, Herrine SK, Isenberg GA, et al. The devil is in the third year: a longitudinal study of erosion of empathy in medical school.Acad Med.2009;84(9):1182-91. doi 10.1097/ACM.0b013e3181b17e55. [PubMed:19707055].

16. Ward J, Schaal M, Sullivan J, Bowen ME, Erdmann JB, Hojat M. Reliability and validity of the Jefferson Scale of Empathy in undergraduate nursing students. J Nurs Meas. 2009;17(1):73-88. doi: 10.1891/10613749.17.1.73. [PubMed: 19902660].

17. Ouzouni C, Nakakis K. An exploratory study of student nurses' empathy. Health Sci I. 2012;6(3):534-52.

18. Wilson SE, Prescott J, Becket G. Empathy levels in first- and thirdyear students in health and non-health disciplines. Am J Pharm Educ. 2012;76(2):24. doi: 10.5688/ajpe76224. [PubMed: 22438596]. [PubMed Central: PMC3305933]
19. Hasan S, Babar M, Kai Chan K, Ahmed S, Mitha S. An assessment of pharmacy students' empathy levels in Malaysia.J Adv Pharm Educ Res. 2013;3(4):531-40.

20. Rosen IM, Gimotty PA, Shea JA, Bellini LM. Evolution of sleep quantity, sleep deprivation, mood disturbances, empathy, and burnout among interns. Acad Med.2006;81(1):82-5. doi:10.1097/00001888-20060100000020. [PubMed: 16377826].

21. Williams B, Brown T, McKenna L, Boyle MJ, Palermo C, Nestel D, et al. Empathy levels among health professional students: a cross-sectional study at two universities in Australia. Adv Med Educ Pract. 2014;5:10713. doi: 10.2147/AMEP.S57569. [PubMed: 24833947]. [PubMed Central: PMC4014368].

22. Trevizan MA, Almeida RG, Souza MC, Mazzo A, Mendes IA, Martins JC. Empathy in Brazilian nursing professionals: a descriptive study. Nurs Ethics. 2015;22(3):367-76. doi: 10.1177/0969733014534872. [PubMed: 24934271].

23. Fields SK, Mahan P, Tillman P, Harris J, Maxwell K, Hojat M. Measuring empathy in healthcare profession students using the Jefferson Scale of Physician Empathy: health provider-student version. J Interprof Care. 2011;25(4):287-93. doi: 10.3109/13561820.2011.566648. [PubMed: 21554061].

24. Kataoka HU, Koide N, Ochi K, Hojat M, Gonnella JS. Measurement of empathy among Japanese medical students: psychometrics and score differences by gender and level of medical education. Acad Med. 2009;84(9):1192-7. doi: 10.1097/ACM.0b013e3181b180d4. [PubMed: 19707056].

25. Suh DH, Hong JS, Lee DH, Gonnella JS, Hojat M. The Jefferson Scale of Physician Empathy: a preliminary psychometric study and group comparisons in Korean physicians. Med Teach. 2012;34(6):e464-8. doi: 10.3109/0142159X.2012.668632. [PubMed: 22435916].

26. Nair S, Shetty RS, Guha S, Anjum Z, Kamath A. Assessing empathy among undergraduate medical students: a cross sectional analysis using the Jefferson scale in a medical school in Coastal Karnataka. Int J Commun Med Public Health. 2018;5(3):953. doi: 10.18203/23946040.ijcmph20180463.

27. Mostafa A, Hoque R, Mostafa M, Rana MM, Mostafa F. Empathy in undergraduate medical students of bangladesh: psychometric analysis and differences by gender, academic year, and specialty preferences. ISRN Psychiatry. 2014;2014:375439. doi: 10.1155/2014/375439. [PubMed: 25006522]. [PubMed Central: PMC4004052].

28. Shashikumar R, Chaudhary R, Ryali VS, Bhat PS, Srivastava K, Prakash J, et al. Cross sectional assessment of empathy among undergraduates from a medical college. Med J Armed Forces India. 2014;70(2):179-85. doi: 10.1016/j.mjafi.2014.02.005. [PubMed: 24843209]. [PubMed Central: PMC4017208].

29. Vallabh K. Psychometrics of the student version of the Jefferson Scale of Physician Empathy (JSPE-S) in final-year medical students in Johannesburg in 2008. South Afr J Bioethics Law. 2011;3(2):63-8.

30. Sedaghati Kasbakhi M, Rohani C, Mohtashami J, Nasiri M. Cognitive or Affective Empathy in Oncology Nurses: A Cross-Sectional Study. Iran J Nurs Res. 2017;12(4):9-18. doi: 10.21859/ijnr-12042.

31. Buyuk E, Rizalar S, Güdek E, Güney Z. Evaluation of Empathetic Skills of Nurses Working in Oncology Units in Samsun, Turkey. Int J Care Sci. 2015;8(1):131-9.

32. Batt-Rawden SA, Chisolm MS, Anton B, Flickinger TE. Teaching empathy to medical students: an updated, systematic review. Acad Med. 2013;88(8):1171-7. doi: 10.1097/ACM.ob013e318299f3e3. [PubMed: 23807099].

33. Pedersen R. Empathy development in medical education-a critical review. Med Teach. 2010;32(7):593-600. doi:10.3109/01421590903544702. [PubMed: 20653383].

34. Kelm Z, Womer J, Walter JK, Feudtner C. Interventions to cultivate physician empathy: a systematic review. BMC Med Educ. 2014;14:219. doi: 10.1186/1472-6920-14-219. [PubMed: 25315848]. [PubMed Central: PMC4201694]. 